\title{
Why Factory1: The Spatial Significance of Architectural Education Buildings
}

\section{Zhu fengjii ${ }^{1}$, Sun leilei ${ }^{1,2}$, Zhu kaiyi $^{2}$, and Jing liping ${ }^{1}$}

${ }^{1}$ Soochow University, Department of Architecture, Suzhou, China

${ }^{2}$ Delft University of Technology, Faculty of Architecture and Built Environment, Delft, the Netherlands

\section{Abstract}

The educational space of the Architecture faculty is used to cultivate architects. At the same time, it becomes the carrier of architectural ideas and teaching methods. The type of architecture and its spatial organization reflect the architectural education philosophy and attitude. Back in history, as early as the Renaissance, there had study places for architects emerged. After the industrial revolution and the modernist process, the types of architectural education sites are more diverse, and their main features are the spatial form of hybrid and box-in-box. This article preliminarily analyzes the

Corresponding Author:

Sun leilei

L.Sun-3@tudelft.nl

Received: 15 March 2019

Accepted: 25 May 2019

Published: 20 November 2019

Publishing services provided by

Knowledge

(c) Sun leilei et al. This article is distributed under the terms of the Creative Commons

Attribution License, which permits unrestricted use and redistribution provided that the original author and source are credited.

Selection and Peer-review unde the responsibility of the Architecture across Boundaries Conference Committee.

\section{S OPEN ACCESS} evolutionary outline of architectural education buildings and interprets the spatial ideas in each period. The study focuses on the famous Dutch architectural school-BKCity of the Delft University of Technology, analyzing the teaching space logic of its distinctive Why Factory and exploring how the related space could stimulate the vitality of architectural education. By the analogy of some architectural schools, it also tries to compare the differences and characteristics of Chinese and Western architectural academies, finding out the spatial significance in architecture discipline, education method as well as sustainable application.

Keywords: School of Architecture, BKCity, Educational Space, Cognitive Experience, Sustainable Application

\section{Introduction}

As the main space of the design curriculum activities for teachers and students, the design of the architectural school not only needs to meet the teaching requirements but also reflects its teaching significance. In addition to providing a place for learning and exchange in the process of dissemination, absorption, transformation and innovation, the space ontology is also an important part of creative thinking. Meanwhile, the plentiful layout of the interior of the pavilion of the school has a positive impact on architectural design. Therefore, the design and utilization of the architecture school play an important role in the development of the architectural discipline. Architecture is a discipline with the primary goal of "creating three-dimensional space and using it for related human 
activities" [1]. Since the development of the discipline, a large number of buildings have been built specifically for architectural education, but according to the characteristics of architecture itself, what kind of teaching space could adapt to the development of the discipline is still a critical question that needs in-depth research and overall discussion. Combining the connection between architectural education and space organization, to create an architectural education space that conforms to the educational philosophy will meet the space ideas of the future architecture college.

\section{Background of Architectural Discipline and Space Development}

\subsection{Architectural education types}

The architectural education mode has developed basically classified three types: the Beaux-Arts Academy, the engineering school and the school in university [2]. First, the Beaux-Arts Academy mode focuses on abstract art, model and graphics performance. Under this mode, architectural design emphasizes conceptual and experimental content. There are many analytical and conceptual illustrations in student work. Most of the assignments are conceptual, and most of the architectural drawings are not completed. Second, the core of the engineering school mode is about how to design a building and starting learning directly from architectural design. Students' drawings mainly focus on the profile and perspective, emphasizing the completion of a design. Third, the university mode is a newly developed-mode, aiming at advancing the development of architecture discipline. It is also known as academic research, which extracts the most basic and core content of the design and trains it professionally

\subsection{Development of teaching places}

In the 17th century, architectural education is part of art education. At that time, the Beaux-Arts Academy mode was first introduced, namely the apprenticeship system. The government built a special building "study house" for architecture education (F1a). Referring to the Italian Renaissance Palace and the Roman Clerical Palace, the designer Felix Dibon revealed classicism which was consistent with the social values at the time. Architecture schools around the world have followed this philosophy of classicism since then. 
In the following industrial revolution period from the 1860 s to 1940 s, new techniques and materials brought a new value system in architecture - the Bauhaus introduced by Gropius. The Bauhaus system was characterized by simplicity and clarity, buildings have become lighter and more transparent compared with architecture during the Renaissance (F1b). The teaching method was nevertheless still the traditional model, based on teacher-apprentice experience. The continuous space in the interior of the building enhances the openness and publicity of the site, which promotes the development of architectural education. As a result, the architectural school began to become a comprehensive building.

Yale Art and Architecture Building ("A \& A Building") is one of the earliest and most famous brutalist buildings in the United States. It was built in 1963 and heralded a major shift in architectural thinking. Architecture department is no longer a clear and multifunctional open space in brutalism. The building in Yale was organized into complex networks through much special small space that are connected together like a maze to form a private space carrying different functions [3]. Dividing many parts of a square box into a lot of public space, and combine them along the central street and the individual study space into the slabs on the street to form a spatial organization method for arranging various spatial elements along the common streamline.

The teaching places have changed in the past hundreds of years $(F 4)$. In contemporary, most buildings in architectural colleges and universities around the world have gradually formed two types: the hybrid type and the box-in-box type [3]. The hybrid type has been a result of the social and cultural transformation generated from the concept evolution of sustainability in 1990. In this respect, the concept of sustainability focuses more on the social and economic aspects, through the method of utilizing old objects and materials to achieve the refurbishment of overall architectural environment. Mainstream at the time has indicated that teaching places could be more suitable for architectural education when such a sustainable idea incorporated into teaching building design. The box-in-box type has been derived from a rapidly changing educational environment in which teaching space becomes full of uncertainty according to the increasing complicated requirements. This type tried to distinguish certain and uncertain space, setting boundaries and flexibility meanwhile, and besides enhancing the effectiveness of the design. For example, the Strelka Institute in Moscow is a typical case of the hybrid type, and the Melbourne School of Design (F1C) designed by JWA/NADAAA can represent the box-in-box type. The design of the Melbourne School of Design emphasizes the carrying function of the central space which is surrounded by studios and other staff offices. There is a square box hanging above the large central 
space as a conference room, this box acts as a buffer zone provided between the public and private areas.
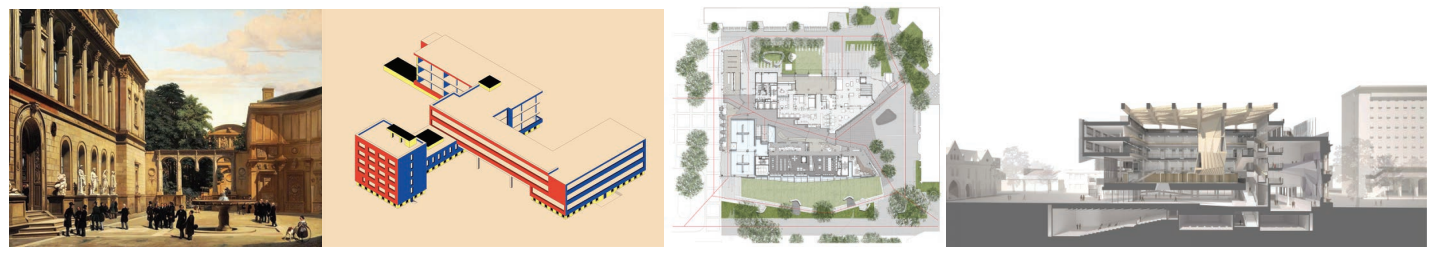

Figure 1: (a) "Art Academy Hall" pain (Image Source: Charles-Leon Pooh (1806 - 1862) "Arts Hall" Oi Painting), (b) Bauhaus Schoolhouse (Image Source: http://www.archcy.com/focus/Bauhaus/), (c) University of Melbourne School of Design (Image Source: http://www.archdaily.com/622708/melbourne-school-ofdesign-university-of-melbourne-john-wardle-architects-nadaaa/).

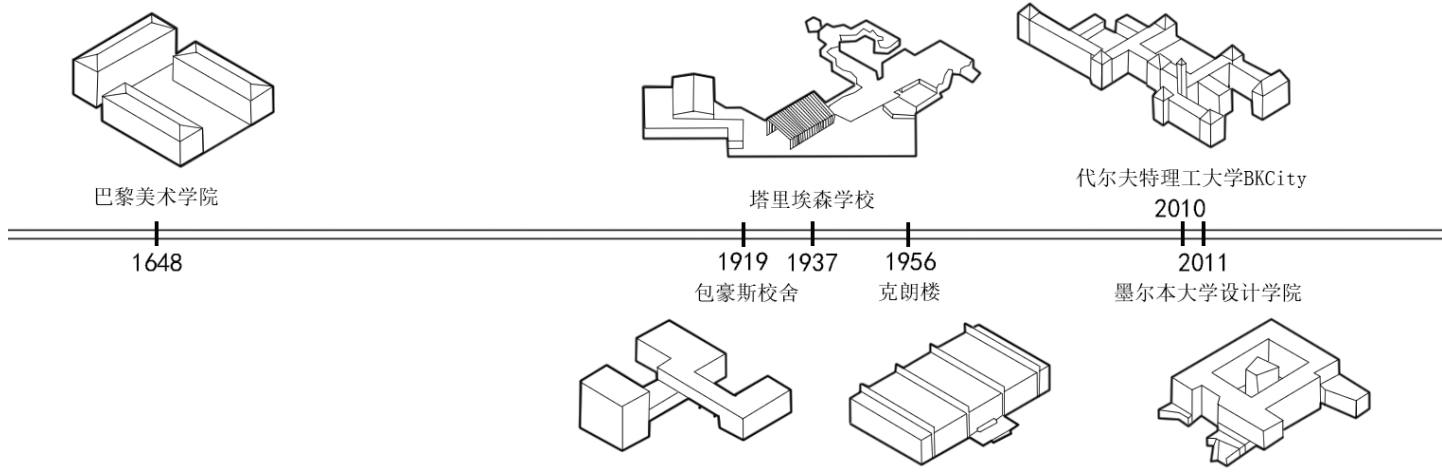

Figure 2: Architecture School Development. (Image Source: Author drawing)

\section{BKCity: Organization Characteristics of a New Architec- tural Faculty Building}

The Architecture and the Built Environment faculty of the Delft University of Technology is named as Bouwkunde in Dutch. "Bouw" means various architectural activities and structures while "kunde" means stands for craft, knowledge and art. There are five departments in this faculty: architecture, architecture engineering+technology, OTBresearch for the built environment, management in the built environment and urbanism [4], sharing a complex building called BKCity (F3a). It was 2008 when a fire accidentally burned down the old faculty building, after the fire, the faculty members decided to move to a historic building and transform it for contemporary architectural education. In the northwest corner of the campus, this newly transformed building contains four floors (F3b) and its large space consists of organized corridors and shared halls [5]. In particular, the corridors are connected in order and divided by a large hall and various small teaching and working space. In this respect, while creating space for interaction 
and communication, this faculty building also provides relatively private workspace and environment.

\subsection{Exhibition space}

Compared with the old faculty building, part of the old corridors with the characteristics of classicism have been preserved. After renovation, the two main corridors have presented a similar scenario as a "street" in any outdoor public space [6]. The first main corridor on the ground floor was designed and decorated with neon billboards, with a bumpy interface, to display students' models and drawings in transparent showcases(F4a). The second main corridor is located near the entrance of the faculty library. This corridor is wider than the first one and combined with display function for academic research, with the names of distinguishing architects on one side of the wall and chair exhibition on the other side [7]. Considering two general tasks for all architecture faculties: pedagogy and research. Chair exhibition space in BKCity has archive the target to utilize the teachers' research results as a resource and provide inspiration to the faculty students. Contents shown in the corridors could complement each other, in order to provide encourage students to think, study, discuss and criticize. The use of such "street" can not only most sufficiently display students' and teachers' works, but also play an effective role for publicity and direction guidance. Corridors in different places are distinguished by different colors, which enhance the spaciousness and brightness of interior space. In addition to these two corridors that serve as display space, there is one dedicated exhibition hall in BKCity, a more vibrant and open "model hall"(F4b). Including the process of making models, presentations in this hall are mainly facing to the public and their evaluation. Therefore, all these mentioned exhibition functions are dedicated to making architectural education more open, which is possible for receiving and providing ideas at the same time.

\subsection{Shared space}

The concept of openness has been emphasized throughout the design. The BKCity faculty building retains a number of semi-public courtyards, by using steel structure and glasses, the adding roof and exterior walls have formed two large space. One hall is situated on the north-south central axis, acting as the center for transportation and a large space for models making. This model-making hall is benefiting from superior locative advantages and environmental advantages. In this hall, the sufficient sunshine 
and light, the layer height and the vibrant atmosphere have attracted students to study and to stay. Directly connecting to the faculty canteen, instead of clear functional division, this type of mixed spatial organization expresses the core idea of the design of the BKCity: Based on the convenience of students. The other hall is located on the west side of the faculty building named as "orange hall" [8] (F4C). This space is highlighted with an obvious and huge staircase, for sitting on and containing lecture rooms. Facing the huge staircase, there is an open space for conferences, design exhibitions and students' self-study. In this sense, collaboration and interaction of collective behavior and individual behavior have been well illustrated in the large public space of the faculty building.

In addition to the orange hall, there is some shared space in the faculty building that is worth learning. The places respectively are staff working space and concealed shared space.

1. Staff working space: Working space more follows a traditional way to organize; nevertheless, in some places, people can overlook the orange hall through window glasses, interacting with the sight lines from the staircase space and feeling the atmosphere from a distance.(F5a)

2. Concealed shared space: On the large staircase platform in the orange hall, as mentioned, there are small meeting rooms of different sizes located on different floors inside the huge orange staircase entity. These relatively concealed shared rooms have become places for teachers and students to communicate and rest at any time.

Cross borders on the other continent, the concept shared hall can also be found in the Southeast University in Nanjing, China. The lower grade adopts large space, dismantling the partition between classrooms and corridors. In this respect, these independent classrooms are integrated as a whole [9], so that students from all majors can learn from each other in a large space. Compared with the BKCity in TU Delft, the educational space of Southeast University lacks interesting components, and its conservative architectural type is contrary to its forward-looking of discipline development. The cognition of subject and object relationship between modern education and traditional teacherstudent relationship has gradually turned to intersubjectivity, which pays more attention to the multi-directional interaction between teachers, students and other people [10]. The mode of open space and the educational environment has stimulated individuals to recognize the importance of interaction between themselves and the others. 

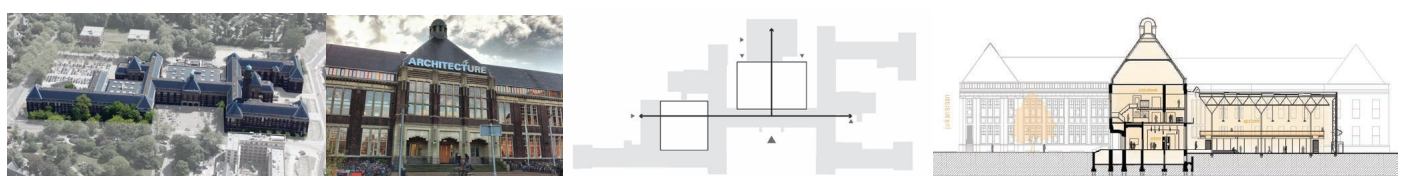

Figure 3: (a) BK City top view and main entrance, (b) BKCity plan and section diagram. (Image Source: http://www.braaksma-roos.nl/project/bk-city/)

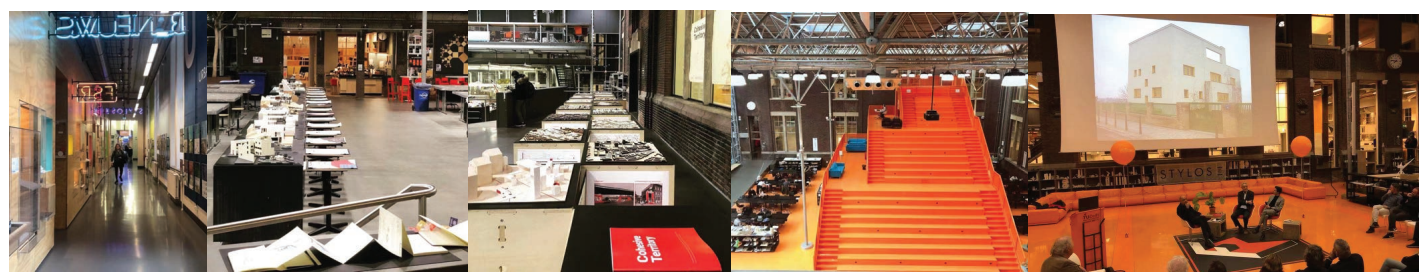

Figure 4: (a) Neon Corridor, (b) Model work hall, (c) Orange Hall. (Image Source: Author shooting)

\subsection{Facilitating space}

There are three leisure places in BKCity that are popular among students and staff: the outdoor bar "De Bouwpub", the ground floor café "Espresso bar" and one faculty canteen. Different design was applied to different places; thus, in addition to the three leisure places, the faculty library, various studio rooms, book stores and students' organizations were following different design strategies, in line with the characteristics of each space. The interior colors, furniture and lighting have become the most attractive details of BKCity. Coincidentally, Frank Lloyd Wright School of Architecture at Taliesin shares many similar design details like this one in Delft. Wright believed that the distant high-voltage poles destroyed the natural landscape of the desert. Thus, in his design, windows of the drawing room, facing the urban main streets, can only allow people inside observe downwards. The mahogany porch on the east side of the drawing room is a transitional space between indoor and outdoor, and the dynamic shadow casting on the ground forms an important scene. For facts that we elaborate above, it seems that color, light and any detailed decoration are crucial for shaping space and spatial relationships.

\section{The Spatial Significance of the School of Architecture}

\subsection{Significance for the discipline development}

According to the basic view of phenomenology, "the building itself is what it is, and the building that people have experienced is the building at this very moment and place itself" [11]. Actually, the existence of architecture begins with the psychological existence 
of human beings, which is the process of figuration and materialization of "design in cogitation". Simultaneously, architecture is an important part of the world and the way to express the meaning of the world [12]. Architectural education space has a variety of specific teaching components, which can be designed and interpreted according to the mainstream teaching philosophy, thus driving students' awareness into learning. Louis I. Kahn once said: Teaching requires space. Teachers and students can sit under a tree and teach in the place that is circled. This is true, teaching may require different external conditions, but it always occurs between people [12]. When teaching must be taken place on a larger scale and be institutionalized, it also involves necessary facilities, such as how many gathering places are needed, what types of gathering points or layouts to make the function work. For teaching, the Architecture Academy should tend to provide space with possibilities and diversities, even though the ideal teaching space is complex and has no fixed form. The contemporary architectural education space has been developed through continuous iteration, forming a new scene with more spatial meanings (F5b, 5c).

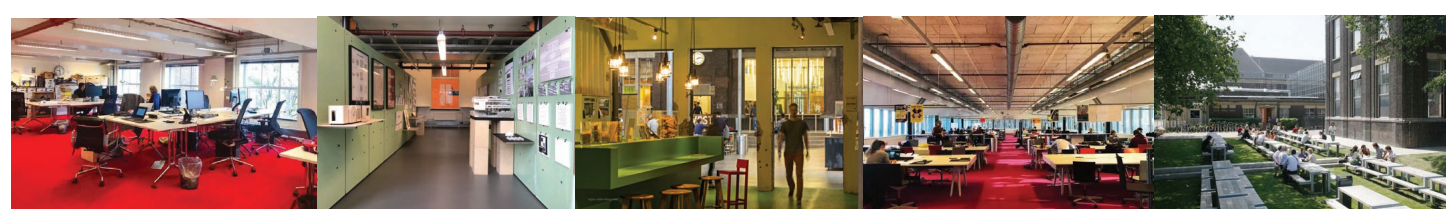

Figure 5: (a) Staff working space (Image Source: Author shooting), (b) Small exhibition hall, Restaurant, Studio, (c) Out space (Image Source: https://www.tudelft.nl/en/architecture-and-the-built-environment/ about-the-faculty/the-building/bk-city-guide/).

\subsection{Education significance of space}

Technology is changing so fast these days that if we couldn't keep learning, we might lose out. So as a medium of knowledge, universities and teaching places will play important roles in lifelong learning. Nowadays, the place such as libraries aren't just about books anymore, but about exchanging knowledge in many ways. Education space has become an active exhibitionist of education itself. Students and teachers can grow with the flow, balance the using of books, strengthen hands-on power, work and play in campus, learn at leisure and think in themes [13]. Space is also the product of society, which is formed by social production method and production relationship and is built by a human's imagination. Based on this theory, education space is created in the light of the needs of teachers and students, that present more enlightened significance as well as teaching atmosphere. The shaping of the education space is to satisfy the students' current and long-term development. Back to the essential 
theme of the space defined by architecture, the form, pattern language and organization of Space are the core contents in architectural knowledge system. Among them, the curriculum always involves the relationship between space and behavior, imparting the transformation strategy between space and function. In this sense, the space ontology of the Architecture Academy can be certainly treated as the main case of design and imperceptible teaching materials.

\subsection{Significance of sustainable application}

In the case of BK, the school moved to another existing building after the old one collapsed by fire and proposed a plan for sustainable expansion and reuse by setting a unique space of architectural education in a newly added courtyard and keeping flexible tables, offices and studios in the old building. In the times of economic development and ecological crisis, the sustainability goal of continuing the history and the future of campus will be achieved through the reasonable transformation for the interior space of the building. Therefore, part of the space has been enlarged with a geometric form which indicates strong identity, which not only shows the dialogue between old and new but contains the superimposed function, including lecture halls, work platforms and entertainment venues in different elevations as well. Also, public functions are carried out along the "inside street" where positive interaction and exhibition activities could take place. In general, diversity and flexibility are two of important characterizations of sustainable strategies, the above method provides the clues for the sustainable use of education buildings and expresses the technical and innovative advantages of the Architecture Academy well.

\section{Conclusion}

When people walk through a building, turning the door handle, touching the surface material and feeling colors, shapes and lights, that will remain in their memories and become a unique experience which is called cognitive experience [14]. These experiences in individual memory become a compound cognition through various expression ways. And it is actually this cognitive experience makes the academy space the carrier and source of architectural education. Space is also diversified due to different educational modes, which have a positive impact on teaching outcomes, students' future development and discipline construction. With the upgrade and extension of technology, the learning environment becomes adaptable and malleable, in which 
ample natural light, ventilation and views are essential. Besides, it is also important to have a spatial organization that encourages casual conversation and high levels of transparency that create visual connection and promote awareness of other activities. And the sensory properties of the materials used may be paid attention to, making sure they are comfortable and attractive [15].

At present, China's architectural education mode is a combination of the engineering college and the Beaux-Arts Academy, and it has entered a new stage including artificial intelligence and digital buildings. Therefore, new requirements are put forward for the teaching space: it is necessary to explore new architectural forms and use different design media to cultivate future architectural talents. Architectural academies in China should express their own ideas or values related to architectural education, in face to the diversified development of teaching space, the spirit in contemporary era and the views of architectural education for the future. To summarize, the very important learning from BKCity and related cases could be that the architectural teaching space is a place where prolific possibilities and spatial imagination can be carried out. Although the connotation and extension of Space cannot be clearly defined, the spatial meaning of the architecture academy inevitably lies in expressing forms of Space, transmitting attributes for Space, and promoting innovation by Space.

\section{Funding}

- Sponsored by the National Natural Science Foundation of China (No. 51508360)

- Sponsored by Jiangsu Oversea Visiting Scholar Program for University Prominent Young\& Middle-aged Teachers and Presidents 2018

\section{Conflict of Interest}

The authors have no conflict of interest to declare.

\section{Citation1}

The Why Factory is a global think-tank and research institute led by professor Winy Maas. It is also the name of the STUDIO of MVRDV's design course in BK and coincides with the ideals and concepts of teaching space and content. 


\section{References}

[1] Qi jie.Space, Place and Life World-— Philosophical Understanding of Architectural Phenomenology[ J].Academic Research,2018(11):35-40+177.

[2] Gu daqing.Beaux-Arts, Polytechnique and University: on the Characteristics of Architectural Education[ J].Urbanism And Architecture,2015(16):1519.

[3] Martijn de Geus,Shang jin.Review of Space for Architectural Education in Western Universities: Typologies and Interior Organization[ J].World Architecture,2017(08):10$19+132$.

[4] https://www.tudelft.nl/en/architecture-and-the-built-environment/about-the-faculty/ departments/

[5] https://www.herbestemming.nu/projecten/bk-city-delft

[6] Tian ni, Shang jin.Faculty of Architecture and the Built Environment, Delft University of Technology Interview with Kees Kaan[ J].World Architecture,2017(08):30-35.

[7] https://www.tudelft.nl/en/architecture-and-the-built-environment/research/ research-facilities/chair-collection/

[8] https://www.mvrdv.nl/projects/64/the-why-factory-tribune

[9] Jiang wenting.Research on the Architectural Education and Architectural Department Hall Design[D].Nanjing University of Technology,2012.

[10] Sun leilei, Huang zhiqiang, Tang chaole. Muti-Transparency and Pervasion: The Potentials of Non-Functional Space[J]. Architectural Journal,2017(06):58-61.

[11] Wang hui.The Significance of Phenomenon-Phenomenology and Contemporary Architectural Design Thinking[J].Architectural Journal,2018(01):74-79.

[12] Zhou yigang, Yuan yue.Asking the Significances of the Building with Dasein:The Inspirations from Heidegger in the Perspective of Phenomenology[ $\mathrm{J}]$.New Architecture,2018(05):155-157.

[13] Enya Moore, Anouk Haegens. New School-Master Class: 8 key strategies for shaping learning space[ J], FRAME, JAN-FEB 2017: p156-175

[14] Yan shurui, Wang shaosen. Theory about Embodiment of Architecture Space Experience Baised on Merleau-Ponty's Body Phenomenology[J].Architecture \& Culture,2017(12):78-80.

[15] Jane Szita, Cindy Baar. Education is no longer just for the young: Francine Houben sees the design of libraries, campus buildings and offices merging[ J]. FRAME, JANFEB 2017: p149-151 